J. Coady, L. Stapleton \& B. Foley (2003). 'TEAMWORK: A Combined Methodological and Technological Solution for E-Working Environments', in Grundspenkis, J, et. al.(eds.), Information Systems Development: Advances in Methodologies, Components and Management, , Components and Management, Kluwer/Plenum Press: NY, pp. 363-372.

\title{
'TEAMWORK': A COMBINED METHODOLOGICAL AND TECHNOLOGICAL SOLUTION FOR E- WORKING ENVIRONMENTS
}

\author{
Jenny Coady, Larry Stapleton, Brian Foley ${ }^{*}$
}

\section{INTRODUCTION}

The word "virtual" describes work that spans one or more discontinuities. The term has been applied to work where people are in discontinuous physical work locations, where work is done in discontinuous time frames, where people have discontinuous organizational affiliations (Watson-Manheim, Crowston \& Chudoba (2002)).

Community is an important aspect of life for most people. Cooley (1983) states that all normal humans have a natural affinity for community. He suggests that the primary factor inhibiting the formation of communities, no matter what their scale, is that they are difficult to organise. Extending the moral ideas inherent in nearly all individuals to the notion of community requires a system or institutional framework. The development and maintenance of such institutions sap the energy of the members of the would-be community and confuse the moral ideals inherent in the notion of community with the project of the institution itself (Fernback \& Thompson (1995)). Given the development of new communications technologies we need to continuously examine the new relations and their potential for new or renewed relationships that arise in this context. Alongside these developments researchers have been advocating the need for a fundamental revision of software technology support in organisations for some time (Wood \& Wood-Harper (1993)). However, few have proposed a basis upon which this progress can be made. This paper argues that new technological forms must recognise that organisational members act in fluid ways and, that organisations are moving towards flexible forms in virtual space. It thus attempts to address this gap in the academic literature, as well as in common practice. The paradigm proposed here is based upon a model of IT, which views organisations in terms of roles operating in particular settings or 'scenarios'. The remainder of this paper briefly reviews a new solution based upon this role-scenario paradigm.

\footnotetext{
* Jenny Coady, I.S.O.L. Research Group, Waterford Institute of Technology, Cork Road, Waterford, Rep. Of Ireland. Dr. Larry Stapleton, I.S.O.L. Research Group, Waterford Institute of Technology, Cork Road, Waterford, Rep. Of Ireland. Brian Foley, Tecnet, Glanmire, Cork, Ireland.
} 


\subsection{The differences between remote and traditional working environments:}

Over the years researchers have highlighted the need for an alternative approach to support technology for organisational information processing. Indeed, the relationship between organisations and the technologies they use to process information has been, and continues to be, a major problem for researchers (Stapleton (2002)). In the 1990's some researchers have returned to fundamental questions of IT support and reviewed many of the basic principles that underlie IT provision. For example, Wood \& Wood-Harper (1993) argued for a 'radical rethink' of IT support, reflecting in many ways the issues raised by Hedberg \& Jonnson (1978) fifteen years earlier, and suggested that software researchers needed to create completely new paradigms for information technology. Since the earliest days of computer-based IT scholars such as McLuhan (1964) have noted that the development of electronic communication technologies has essentially abrogated space and time so that we live in a boundless "global village". Boorstin (1978) argued that communication technology creates ties; bind nations into a new type of community, which he terms the "Republic of Technology". The most recent communication technology development within the post-industrial era is commonly termed Computer-Mediated Communications (CMC). Comprised of different systems such as Electronic mail, bulletin board systems, and real-time chat services, CMC is both an interpersonal, one-to-one medium of communication as a one-to-many or even many-to-many form of mass communication. With an estimated 25 million CMC users worldwide, and this still growing (Calem (1992)) computer mediated communications have the potential to affect the nature of social life in terms of both interpersonal relationships and the character of the community. Virtual communities encompass the economic, political, social and cultural dimensions of community postulated by Van Vliet \& Burgers (1987). Communities have been affected by electronic media's undermining of the relationship between location and access to information so that 'physical location now creates only one type of informationsystem, only one type of shared but special group experience" (Meyrowitz (1985) p 143-4)

Furthermore, it is well understood that electronic group dynamics are not the same as face-to-face and tend to have unpredictable consequences for those attempting to streamline organisational communication (Sproull \& Kiesler (1993), (Stapleton (2001))..

\section{ROLES \& SCENARIOS}

Most modern organisations cannot function effectively without information systems support, but they struggle to live with them in a harmonious relationship (Mc Bride (1999)). They experience a series of gaps, or mismatches, associated with the assumptions, which underpin information systems practice as regards organisational structure, dynamics and the various realities with which organisations must grapple. There are also conflicts associated with the system models, the resulting technological artefacts and many other aspects of the IT domain. Indeed, it has been shown on many occasions that our approach to eliciting and understanding technological and system requirements is typically at variance with the social environment the systems are intended to support (Stapleton (2000)).

In systems design, system components identified by an analysis of the functions to be performed by the whole are intended to fit each other so as to work together harmoniously as well as efficiently and effectively (Hamilton (1997)). However, when it comes to the interaction between users and the technology, this is rarely the case (Davenport (1998), Stapleton (2001)). Researchers have argued that the mechanistic approaches which typify information systems methods are based upon a functionally rationalistic paradigm which 
needs to be reviewed and revised. This paper proposes the adoption of roles \& scenarios (i.e. a model of the social/task setting in which roles are played out) as basic modelling constructs. These constructs are then used to determine system functionality in terms of an organisation of documentation and contracts. This concept drives information systems thinking in a new direction and fundamentally plants both the design process and the technology itself in the organisational space, both in terms of process and language. So, whilst in itself role-based methods and scenario modelling (as separate approaches) are not new, the unique combination adopted here, and the configuration of the methodology with the technology, is highly innovative.

Scenarios can be understood in a number of ways. They can be a sequence of activities, or a more or less richly branded structure of such sequences. They can represent parallels or alternatives, or various intermediate options (Alexander (1999)). Branches can represent alternatives or parallels, or various intermediate options. Scenarios can assist in all phases of the systems life cycle. They can clarify systems scope; help to identify stakeholders, situations, and needs. They can also aid in the organisation of requirements, guide design and coding and also provide scripts for testing. But throughout the cycle their main contribution is perhaps simply to improve project communications between all the groups of people involved.

\section{MODELLING ROLES \& SCENARIOS IN A VIRTUAL ENVIRONMENT}

The model is a common language: the users who are providing the information about the system readily understand it. Using working models, users and analyst's work together to reach an identical understanding of the requirements. Once the model is agreed, the system is implemented by building a real-world version of the model (Kerth (2001)). In Systems and Software Engineering, there are perhaps more schools of thought concerning IS notations and method that on any other topic (Alexander (1999)). One key function of scenarios is to help people communicate about the systems they are involved in. The choice of representation would ideally be a pragmatic one - people selecting the best for their situation.

This paper proposes a role-centred approach for primarily pragmatic reasons. Firstly, people identify themselves better with roles than functions and thus feel more able to understand the system and, hopefully, helping them to focus upon to role ownership. Evidence for this appears in (Warboys, et. al. (1999)). Role models design roles and identify explicitly information flows between them. This information flow based architecture is needed for later implementation in an remote working organisation (such as over the intranet or internet), which is the essence of a virtual work setting. Workflow based structures can be easily derived from role models following a defined set of rules which can be pre-determined and are widely used in industry (Warboys, et. al. (1999))

A scenario workshop can represent a sequence of tasks directly by role-play. A task can be described verbally by a player, or acted out in a variety of ways. The execution path can be symbolised by passing a token, such a juggling a ball to the player whose turn it is next. Both singly- and multi-threaded scenarios can be simulated in this way. Stakeholders see, often for the first time, how their tasks relate to the overall process, and many misconceptions and confusions can be banished in a playful workshop (Alexander (1999)). A similar approach was adopted in object oriented BPRE as laid out in Graham (1994), but has received little attention in the context of roles as specified here.

One of the best-known representations is the idea of Use Cases and UML (Jacobson (1992)). This supposes that the world of business is divided into neatly addressable cases where a user interacts with a system. Graphically a stick person connected to an elliptical 
bubble depicts it. Each bubble depicting a use case, and a number can be arranged into a list to form a diagram. The norm is to arrange them vertically, which does not imply sequence and this can visually be misleading. There has been much debate about whether a use case is simply another synonym for scenario (Alexander (1999)). The question could be answered by obtaining a precise definition of both terms, were it not for the elasticity of both terms. Hence UML notation can be helpful, but currently only goes part of the way towards resolving modelling differences.

\section{4. 'TEAMWORK'}

The TeamWork initiative grew out of developments in the automotive industry in the early 1990's (Messnarz et. al. (1999)) Large firms in this sector realised that in supply chains they work together in kinds of virtual organisations and that borders could not be easily drawn between enterprises. This mirrored experiences elsewhere in industry as outlined in Darnton \& Giacoletto (1992), Davidow \& Malone (1993), Drucker (1988, 1993) and elsewhere. The TeamWork research project involves three main axes, as shown in figure 1. This paper focuses upon the information systems development support aspects of the project, and therefore addresses itself to the Methodology and Technology components of TeamWork. It recognises the importance of new organisational forms and is targeted at communities of workers whose members come together for specific projects, but may not be part of the same organisation or inhabit the same geographical space. The power of such communities, and the risks involved in such organisational forms, are outlined elsewhere (Sproull \& Kiesler (1992)). TeamWork delivers a holistic solution based upon the concepts embodied in a role/scenario organisational perspective. This holistic solution comprises BESTREGIT as a methodological component and NQA as an information and coordination technology based upon organisations as comprising roles and scenarios.

The basic advantages of this approach to information systems development and organisational support include the following:

People will be more aware of their responsibilities and clearly understand communications interfaces to other virtual organisation members. Role-based solutions are specifically adopted with this in mind.

New staff can be more easily integrated through clear role assignments, skill acquisition for the roles and clear appreciation for information and communication flows within the community. Sproull \& Kiesler (1993) show that this is a specific opportunity presented by CSCW systems which support virtual communities.

Information technologies can be deployed which support virtual community communications, documenting of activities and configuration of results in a highly effective manner. This is primarily achieved by making the communications interfaces highly visible, a central deficiency of many current CSCW and ISD approaches which focus on highly functionally rationalistic views of organisational behaviour (Stapleton (2000), Stapleton \& Murphy (2002)). 


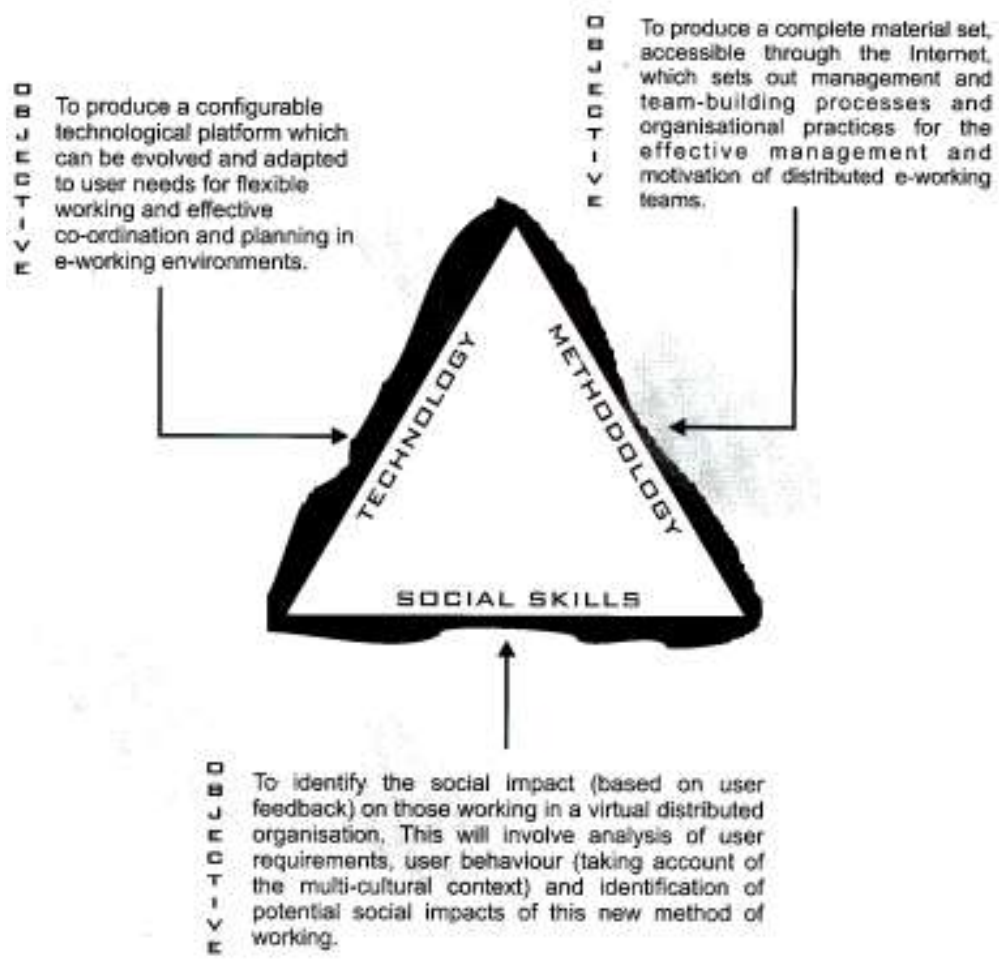

Figure 1: The TeamWork Research Project - Major Axes

Studies examining the effectiveness of this paradigm suggest that significant advantages exist where such an approach is adopted. Indeed preliminary studies of software development projects conducted in Ireland, Austria, Spain and Germany show potential benefits to firms, which adopt technologies based upon this approach (Messnarz \& Tully (2000); Messnarz, et. al. (1999)).

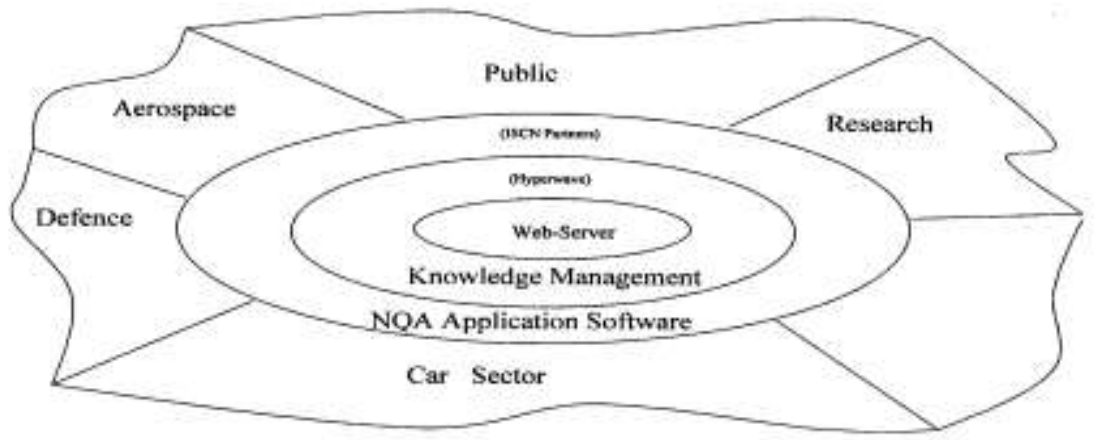

Figure 2. The Basic Technology Platform Architecture

Technologically TeamWork is constructed using Hyperwave's Knowledge Management solution. The key innovation is in the organisational coordination utilities supplied via a combination of NQA technology and the BESTREGIT Methodology. 


\section{BESTREGIT:}

The Teamwork research project believed that the Best Regional Innovation Transfer (BESTREGIT) modelling approach could be used as a trigger for the development of an 'Innovative Organisation' through a life long learning philosophy. The research approach adopted in the TeamWork Project (2001) had to do with formally examining the work scenarios behind an organisations business fields. Through this analysis TeamWork came to a greater understanding of the roles people in organisations play, how those roles interact to produce results, and how TeamWork could track the progress of these results. Once a team view, defined to be a commonly understood mission and goals, has been achieved, then the next logical step was to improve the work scenarios so that those goals can be met. In the modern era work goals are as such that a single individual, operating alone, cannot easily perform their work (Nurmi (1996)). Communication and work coordination is needed, and scenarios are designed aiming at productivity. It is apparent that this approach is based upon a view that business and organisational modelling takes precedence over more traditional information models as are used in SSADM or other structured methods (van Reijswoud \& Mulder (1999)). Instead, the research adopted a view that role/scenario modelling (as a case of business/organisational modelling) can usefully depict information processing in an organisation, and be used directly to configure a complex IT solution.

A major success factor in the transformation from goal trees into TeamWork-based processes is to set the right priorities for the organisation (Warboys, B., Kawalek, P., Robertson, I., \& Greenwood, M. (1999)). In real business cases, unlike the BESTREGIT research, it is often not possible to model all work scenarios, often due to time demands and limited resources. However if a business field with a typical work scenario is selected then there is a re-use factor whereby, once defined, they can be re-used in various models.

Each organisation is viewed as a set of work scenarios, typical examples of these include customer handling and service delivery. A work scenario is therefore a description of the best-perceived way in which to conduct a certain business case in the organisation. In BESTREGIT work scenarios are described with two complimentary views. Firstly as role models, which depict roles as enacted by individuals. One person can play many roles as well as many people playing just one role. Roles exchange information and work results. This information flow between the roles forms the role model. The second view is the workflow models, which consist of a network of work steps. These produce results that can be used by other work steps, each step requiring resources.

BESTREGIT uses an integration of both of these views. Firstly the role models are analysed and designed. Secondly the role models are transformed into workflow views. Then both models are integrated so that a work scenario according to BESTREGIT can be defined as so that people are assigned to roles, roles are assigned to activities, activities are part of a network of work-steps, activities produce results, and roles use resources to perform the activities.

These relationships are then defined for a certain business case of the organisation to have a description of the best way to perform the business case. Once process have been modelled using BESTREGIT it becomes possible to think about optimally organising all their elements for greater effectiveness and efficiency.

\section{NQA - A NEW DEPARTURE IN CMC:}

NQA is a CMC system based upon a role-scenario view of organisational behaviour. The initial concepts, which are reified in NQA, are the basic building blocks upon which 
BESTREGIT was constructed. NQA comprises important concepts in the context of information systems development through configuration:

1. Development by Configuration

2. Re-Use Pool - Organisational Function Based Configuration

\subsection{Development By Configuration}

This paradigm takes data independence objectives as its underlying principle with the added notion that data can be assigned with functionality by the user through specific configuration techniques. Such an approach overcomes problems often associated with component based approaches to software development, particularly those associated with the object oriented paradigm in which configuration of data (attributes) and methods (functions) is inseparable because both data and functions are encapsulated into a single, inviolable object (Graham (1991), Atzeni et. Al. (2000)). The Object Oriented paradigmatic approach has often been mooted for advanced coordination systems and methodologies for CSCW, Business Process Re-Engineering (BPRE) and other approaches associated with organisational transformation (Malone (1992), Shelton (1994)). However, this research present recognises that, whilst superficially the purely object-oriented paradigm may seem attractive, it does not reflect basic organisational information processing as it occurs in virtual communities. This fit between organisational information processing (as well as other organisational properties) has been shown to be important elsewhere, particular for groupware-type systems (Kraut et. al. (1994), Rogers (1994)). NQA must maintain the power of object-orientation by storing document objects etc. but a paradigmatic shift towards data independence assumptions is also required in order for the system to adequately reflect organisational behaviour in virtual spaces. This is an important theoretical shift which is required in order to effectively place NQA as a solution for virtual communities.

In role-based views, the data and function in organisational information processing are fundamentally separated and this must be reflected in the supporting technological architecture. In this approach users can insert and maintain document or result templates and adapt the system to their own specific documentation requirements without any change or customisation of code (just by configuration of data). Whilst documents are stored in an object-based technological solution (ensuring that the power of objects is harnessed), NQA also provides for a data independence rationality, which is usually seen as fundamentally opposed to object orientation. The reconciliation of these two rationalities is fundamental to NQA.

\subsection{Re-Use Pool Concept (Organisational Function Based Configuration)}

The Re-use pool contains a series of objects that can be reused in order to configure NQAs virtual office and enable the user to tailor the system. At the moment the following basic elements can be configured to which the above functionality is generated.

Tasks - A submission of a document and/or report automatically selects roles (role based configuration) which should receive this information and creates tasks for the users playing these roles. These tasks can then be traced.

Documents - There is a standard user interface for offering documents in the virtual office. Documents fall under the configuration management utility, and they can be linked with reports and other documents, can be downloaded, edited, and uploaded, and submitted to a team. 
Reports - Reports usually are forms to be filled in, linked to a document, and submitted to a team.

Linked Reports - these are treated the same as regular reports, plus the link report is automatically linked by its creation backward and forward to a predefined set of reports and documents.

Depending on the user needs the elements are configured within a project administration structure. For example, Feature Requests (FR) can be linked with User Requirements Documents (URD), so that an URD is automatically created by the links to accepted FRs. Further basic elements are under consideration for insertion into the NQA configuration pool in later releases. This is possible because of the relatively easy extensibility provided by the object-oriented structure in NQA.

\section{PRELIMINARY STUDY}

\subsection{An outline of the Research Approach}

The preliminary training of users of the NQA configured system took place over 3 days involving 20 people enacting various roles within the system. The research data was gathered by open-ended questions, which were not defined with any particular structure. Rather, the participants were encouraged, ion their own words, to describe their experiences with working with the NQA system. No assumptions were made as to the likely experiences of the participants in working with the system. This provided oral, open feedback to the research team. This was felt to be more appropriate than a questionnaire based approach, due to the exploratory nature of the work and follows other similar approaches where a preliminary study was utilised (Stapleton (1999a), Stapleton (2001)). This data gathering approach was informed by hybridised grounded theory as per Miller \& Dunn (1998) and Stapleton (2001) and loosely informed by Glaser \& Strauss (1967).

\subsection{User Responses}

The key findings of this preliminary study can be summarised as follows:

1. The general approach used to organise document exchange was useful due to the explicit definition of roles and the scenarios in which the documents were to be exchanged and processed

2. The security aspects of the system were important for virtual office scenarios. Participants felt that the explicit management of security according to the role of users was very suitable for virtual working where perceptions of security were critical

3. The ability to lock documents, ensuring they can be read but not modified, when they are presently being worked on in a shared environment, was also critical to the perceived usefulness of the system and helped organise user interactions in the virtual space, which would otherwise have been difficult to manage coherently

4. Political realities, which were typically hidden to members of rapidly created virtual work groups, were highlighted explicitly by the use of role-based modelling, particularly when combined with the scenarios in which these roles would be enacted.

5. The use of goal-trees to organise the document navigation system was inappropriate and lead to a deal of confusion and difficulty in document processing 
6. People were often unhappy with the explicit codification of certain roles. The research assumes that roles will be adopted without question by the participants. Instead, participants often questioned the roles as outlined in the NQA system, even when they participated in the definition of these roles during design and pre-configuration stages

The above findings illustrate the strengths and weaknesses of the research position adopted here. Despite this only being a prototype, trial system it is apparent that, despite some fairly serious caveats, users did find the approach and the technology useful for informing and supporting virtual office activities. Firstly, the importance of security and integrity in the virtual environment increases. This is possibly due to the fact that people are working remotely and lack the tangible contact of face-to-face contexts so that certain sensitivities about information are amplified. Whilst this was not explicitly tested in the preliminary study, it would fit with the findings of other researchers, especially the work of Sproull \& Kiesler (1993). Little research has been done on the perceived importance of integrity and security in virtual work environments as they envisaged in this study, and these issues should be scrutinised during a more formal social analysis (see discussion below). This is particularly true of integrity, as the particular dynamics of virtual offices creates an environment in which version management is critical but can create severe problems where there are quite informal processes such as those associated with the creation of a research proposal in virtual space. The importance of integrity for complex, dynamic and distributed objects is well documented elsewhere and reflected in developments in object oriented database technology and other database technologies (Brown (1991), Loomis (1992)).

Users described how the system helped them to make explicit the political realities associated with the processes in which they were involved. This was a direct result of the emphasis upon roles (loci of power and influence) and scenarios (enactments of power and influence). The researchers had not expected this issue to emerge as important as it receives relatively little attention in the literature on ISD. This therefore needs further analysis and will probably require refinements to the methodology. These findings do reflect some work on politics in ISD, in particular early work by Lynn Markus (Markus (1984) and some more recent work suggesting that a greater emphasis upon political realities is required during ISD (Cernetic \& Hudovernik (1999), Stapleton (2001)).

The most serious problem which emerged during the training was associated with the use of goal-trees. The literature on virtual organisations suggests that it can be easy for members of virtual, asynchronous groups to become distracted by the needs of their physical settings and that attention needs to be focussed in order to ensure that people devote the necessary energy to the virtual project group (Sproull \& Kiesler 1993), March (1999)). In order to ensure that the virtual group remained 'on-track', and in compliance with a role-based approach, goal-trees were adopted as a means by which document processing activities could be organised according to explicitly defined objectives. This goal-orientation was seen to be a critical aspect of the NQA system and was intended to obviate problems associated with typical virtual group problems as documented in the organisational studies literature. It is apparent from the preliminary feedback that this assumption may be inappropriate for virtual work settings. Furthermore, the codification of certain roles proved to be quite problematic. It became difficult to obtain agreement of users as to the roles they had adopted, even when they had been part of the process by which the system was configured according to those roles. Further research will be required to assess the extent to which these issues can be successfully addressed. Indeed, it is possible that the extent to which any technology can successful codify the activities of a virtual group may have been reached in NQA. Researchers have argued for sometime that the functionally rationalistic perspective of organisational information processing, as reified in IT solutions, is not always appropriate, and that alternative perspectives require 
development, particularly as codification (Moreton \& Chester (1999), Probert \& Rogers (2000)).

Whilst the idea of a role based system is not new (Warboys, B., Kawalek, P., Robertson, I., \& Greenwood, M. (1999)) it is readily apparent that more research is needed in order to understand the information processing dynamics associated with this approach. This is especially true for technologically mediated groups which operate in virtual settings, especially where those technologies are developed according to a combinatory role/scenario model. In the next stage of this research, a formal social analysis will be carried out in order to more fully understand the relationship between the technology and the participants, in order to address the issues identified above.

Finally, there were difficulties associated with the use of the primitive prototype. Some of these difficulties included the delving deep into an un-user friendly interface to access documents and folders. The ability to assign access rights, leave messages and update notes came with the price of having to navigate through several windows before perhaps stumbling upon the correct screen. Whilst these problems are also associated with the use of goal-trees, it was predicted that some difficulties would be experienced with the use of such a prototype. Further research and testing will be required in order to isolate the specific problems in this space.

\section{CONCLUSION \& FUTURE DEVELOPMENTS}

This paper presents a new technology, which has been developed to prototype stage, and is based on an alternative view of organisational information processing. The next stage is to perform a full system test of the technology, and its underlying methodology. To this end, the research team have organised a full test with naïve users. This test will involve a scenario in which several research partners develop a research proposal across several countries. Participants in the test include research agencies as well as researchers in technical universities across Europe. Specifically, the countries involved are Ireland, Austria and Slovenia. This test is organised and will get underway shortly. The success of this test will not only be measured by user feedback, but also by the successful completion of a research project to proposal (and hopefully funding) stage. Thus the test process utilises NQA in a real-life scenario, and involves major stakes for those involved. It is intended that such an approach will yield the best possible usability data and reflects recent thinking in information systems development as regards training and learning (Stapleton (2000), O’Keeffe (2001)).

The Teamwork approach combines role and scenario based approaches into a coherent methodology. This methodology is then reified in a new virtual office technology called NQA. The virtual office environment and, in particular, the social relationships which make such an environment work, are strongly reflected and supported by such an approach. Consequently, NQA is a very promising system with regard to highly dispersed organisations, even though it is only in its preliminary phase. Preliminary studies show that there is empirical evidence for merit in such an approach, although the evidence still requires further corroboration. Consequently it is important for this research to progress to a full test in a relatively complex user environment. This full testing phase is scheduled and will be conducted for a remote work environment where a complex set of social interactions must be supported. With certain caveats, the evidence to date suggests that the basic methodology and technology will be successful although it is likely that modifications will be necessary for the prototype NQA system. This paper presents the results of a research study which has culminated in a working prototype based upon a new IT view of organisational behaviour, a view which is far closer to the reality of virtual work than 
previous systems or approaches. Further research must be carried out in order to obtain substantial test results across a large community of users. Furthermore, other researchers must build upon role-scenario based approaches in order to confirm, or otherwise, the general applicability of the approach across a variety of user domains. One area of potential development is the inclusion of intelligent agent technologies, which interpret and update user profiles, thus obviating the extensive tree searches, which are required in goal treetype systems such as adopted in NQA. Whatever the case, it is readily apparent that NQA represents a radical new approach to IT support in remote working environments. This approach is both innovative and potentially opens an array of new possibilities - which are the subject for future research.

\subsection{Acknowledgements:}

The authors gratefully acknowledge the financial support for this project provided by the European Commission as part of the IST programme of FP5 (IST-2000-28162). The authors also gratefully acknowledge the help of the reviewers in revising early drafts of this paper.

\section{REFERENCES:}

Alexander, I. (1999), Migrating Towards Co-operative Requirements Engineering. CCEJ, 1999, 9, (1), Scenario Plus User Guide and Reference Manual, http://www.scenarioplus.org.uk. pp. 17-22

Boorstin, D. (1978), The Republic of Technology: reflections on our future community, Harper \& Row, USA. Brown, A. (1991). Object-Oriented Databases: Applications in Software Engineering, McGraw Hill: NY.

Calem, R. (1992), The network of all networks, New York Times, December $6^{\text {th }}$, p. 12.

Cernetic, J. \& Hudovernik, J. (1999). The Challenge of Human Behaviour Modelling in Information Systems Development, in Evolution and Challenge in Systems Development, Zupancic, J., Wojtkowski, W., Wojtkowski, W.G., Wrycza, S., (eds.), Kluwer Academic/Plenum Publishers: New York, pp. 557-567.

Cooley, C. (1983), Social Organization: A Study of the Larger Mind, Transaction Books, New Brunswick, NJ. Darnton, G. \& Giacoletto, S.(1992), Information in the Enterprise: It's More than Technology, Digital: MA.

Davidow, W. \& Malone, M. (1993), The Virtual Corporation: Structuring and Revitalising the Corporation for the 21st Century, HarperBusiness: NY.

Davenport, T (1998). Putting the Enterprise back into the Enterprise System.' Harvard Business Review, August, 76, 4, pp. 121-131.

Drucker, P. (1988). 'The Coming of the New Organisation', Harvard Business Review, Jan-Feb pp.45-53.

Drucker, P. (1993). Post-Capitalist Society, Butterworth-Heinemann Ltd: Oxford.

Fernback, J. \& Thompson, B. (1995), Computer Mediated Communication and the American Collectivity: The Dimensions of Community Within Cyberspace, presented at the Annual convention of the International Communication Association, Albuquerque, New Mexico.

Glaser, B. \& Strauss, A.(1967).The Discovery of Grounded Theory: Strategies for Qualitative Research, Aldine: Ill.

Graham, I. (1994). 'Business Process Re-engineering With SOMA', in Proceedings of Object Expo Europe Conference, SIGS: NY, pp. 131-144

Hamilton, A. (1997), Management by Projects: Achieving Success in a Changing World, Oak Tree,Dublin.

Hedberg, B. \& Jonsson, S. (1978). 'Designing Semi-Confusing Information Systems for Organisations in Changing Environments', Accounting, Organisations \& Society, 3/1 pp. 47-64.

Jacobson, I (1992), Object-Oriented Software Engineering: A Use Case Driven Approach, Addison-Wesley.

Jones, Q. (1997), Virtual Communities, virtual settlements and cyber-archaeology: a theoretical outline, Journal of Computer Mediated Communication, 3(3).

Kerth, N. (2001), Project Retrospectives: A Handbook for Team Reviews, Dorset House, NY.

King, M. (1996), On Modelling in the Context of I, JTCI Workshop on Standards for the use of Models that Define the Data \& Processes of Information Systems.

Loomis, M. (1992). Advanced Object Databases, Object Expo European Conference Proceedings, SIGS: NY.

March, J.G. (1999). The Pursuit of Organisational Intelligence, Blackwell: Oxford.

Markus, L. (1984). Systems in Organisations: Bugs \& Features, Pitman.

Markus, L. \& Robey, D. (1988). 'Information Technology and Organisational Change: Causal Structure in Theory and Research', Management Science, 34/5, May, pp. 583-598. 
Mc Bride, N. (1999), Chaos Theory and Information Systems Track 4: Research Methodology and Philosophical aspects of IS research, www.cms.dmu.ac.uk/ nkm/CHAOS.htm

McLuhan, M. (1964), Understanding Media: The Extensions of Man, McGraw-Hill, NY, USA.

Mehrabian, A. (1971). Silent messages. Wadsworth, Belmont, California

Meyrowitz, J. (1985), No Sense of Place: The Impact of Electronic Media on Social Behavior, Oxford University Press, NY, USA.

Miller, K. \& Dunn, D. (1999). 'Using Past Performance to Improve Future Practise', in Zupancic, J., Wojtkowski, W., Wojtkowski, W.G., Wrycza, S., (eds.), Evolution and Challenge in Systems Development, Kluwer Academic/Plenum Publishers: New York, pp. 99-107

Moreton, R. \& Chester, M. (1999). 'Reconciling the Human, Organisational and Technical Factors of IS Development', in Evolution and Challenge in Systems Development, Zupancic, J., Wojtkowski, W., Wojtkowski, W.G., Wrycza, S., (eds.), Kluwer Academic/Plenum Publishers: New York, pp. 389-404

Nocera, J. (1998), Cultural Attitudes Towards Communication and Technology, University of Sydney, 193-195.

Nurmi, R. (1996), Teamwork and Leadership, Team Performance Management: An International Journal, $2,1$.

Probert, S. \& Rogers, A. (2000). 'Towards the Shift-Free Integration of Hard \& Soft IS Methods', in Systems Development for Databases, Enterprise Modelling \& Workflow Management, Wojtkowski, W., Wojtkowski, W.G., Wrycza, S., Zupancic, J., (eds.), Kluwer Academic/Plenum Publishers: NY.

Rheingold, H. (1993), The Virtual Community: Homesteading on the electronic frontier, Addison-Wesley, MA.

Sproull, L. \& Kiesler, S. (1992), Connections, MIT Press: MA.

Stapleton, L. (1999). 'Positivism, Interpretivism \& Post-Phenomenology - Views of an Organisation in Flux: An Exploration of Experiences in a Large Manufacturing Firm', in Proceedings of the European Colloquium of Organisational Studies (EGOS 1999), University of Warwick: UK.

Stapleton, L. (1999a). 'Information Systems Development as Interlocking Spirals of Sensemaking', in Zupancic, J., Wojtkowski, W., Wojtkowski, W.G., Wrycza, S., (eds.), Evolution and Challenges in Systems Development, Kluwer Academic/Plenum Publishers: New York, pp. 389-404

Stapleton, L. (2000). 'From Information Systems in Social Settings to Information Systems as Social Settings', Proceedings of the 7th IFAC Symposium on Automation Based on Human Skill: Joint Design of Technology and Organisation, Brandt, D. \& Cerenetic, J. (eds), VDI/VDE-Gesellschaft Mess- und Automatisierrungstechnik (GMA): Dusseldorf, pp. 25-29.

Stapleton, L. (2001). Information Systems Development: An Empirical Study of Irish Manufacturing Firms, Ph.D. Thesis, National University of Ireland

Stapleton, L. \& Murphy, C. (2002). 'Examining Non-Representation in Engineering Notations: Empirical Evidence For The Ontological Incompleteness of The Functionally-Rational Modelling Paradigm', in Proceedings of the International Federation of automation and Control World Congress, Forthcoming.

Teamwork (2001), Periodic Progress report No.1 of the TeamWork Project.

Van Reijswoud, V. \& Mulder, H. (1999). 'Bridging the Gap Between Information Modelling \& Business Modelling for ISD', in Evolution and Challenge in Systems Development, Zupancic, J., Wojtkowski, W., Wojtkowski, W.G., Wrycza, S., (eds.), Kluwer Academic/Plenum Publishers: New York, pp. 317-330.

Van Vliet, W. \& Burgers, J. (1987). Communities in transition: From the industrial to the post-industrial era. In I. Altman \& A. Wandersman (Eds.), In Neighborhood and Community Environments. Plenum: NY.

Warboys, B., Kawalek, P., Robertson, I., \& Greenwood, M. (1999), Business Information Systems: A Process Approach, McGrath Hill, UK.

Watson-Manheim, M. B., Crowston, K. \& Chudoba, K. M. (2002), A new perspective on "virtual": Analysing discontinuities in the work environment. Presented at HICSS-2002, Kona, Hawaii, USA.

Wood J.R.G. \& Wood-Harper, T. (1993). 'Information Technology in support of individual decision making', Journal of Information Systems, 3/2, April, pp. 85-102. 